\title{
Parameterized, numerical design of a two-wheel Curtis steam turbine for small scale WHR
}

\author{
Philipp Streit $^{1 *}$, and Andreas P. Weiß ${ }^{1}$ \\ ${ }^{1}$ OTH Amberg-Weiden, Center of Excellence for Cogeneration Technologies, Kaiser-Wilhelm-Ring \\ 23, 92224 Amberg, Germany, +49 96214823531
}

\begin{abstract}
In contrast to the current trend of converting waste heat into electricity in the small power range below $100 \mathrm{~kW}_{\mathrm{el}}$ by means of an ORC plant, the authors are pursuing the concept of a micro steam power plant equipped with a micro turbine. Water avoids many of the problems often associated with organic working fluids, such as flammability, toxicity, greenhouse gas effect and high fluid costs. However, water vapor makes turbine design more challenging. The physical reasons for this are repeated, and thereby it becomes clear why a velocity compounded two wheel Curtis turbine has been chosen. The used in-house 1D turbine design tool is briefly introduced. More focus is put on the shortcomings of the implemented 1D loss model and their negative impact on the current turbine design. Consequently, the authors continued actual turbine design by a parameterized approach in 3D CAD/CFD. This approach is explained, and finally, the CFD flow field and the performance maps of the designed turbine are discussed. The turbine is currently under construction and will be installed in 2022 in a waste heat recovery (WHR) plant in Nuremberg/Germany.
\end{abstract}

\section{Introduction}

Waste heat recovery (WHR) is an important building block towards an increase in energy efficiency in industry and for a successful energy transition. Pehnt et al. 2010 [1] reported that about $80 \mathrm{TWh}$ of waste heat $>140^{\circ} \mathrm{C}$ are rejected yearly only in the German industry. Assuming a conversion efficiency of about $10 \%$, which is realistic for small WHR units, 8 TWh per year could be extracted. This is the annual electricity production of a $1000 \mathrm{MW}$ steam power plant. In cases where the waste heat temperature is below $300-350{ }^{\circ} \mathrm{C}$, an ORC system is currently the preferred solution for waste heat recovery [2]. In large Combined Cycle Power Plants (CCPP), a steam turbine reuses the waste heat of the upstream gas turbine $\left(500-600{ }^{\circ} \mathrm{C}\right)$, which leads to an overall electric efficiency of more than $60 \%$ [3]. The main advantage of an Organic Rankine cycle (ORC) is the higher vapor pressure of an organic fluid compared to water for a given heat source temperature [2]. Thanks to this, a low temperature heat source can be exploited more effectively. However, the maximum cycle temperatures of ORC are limited to $300-350{ }^{\circ} \mathrm{C}$ due to the danger of degradation of the working fluid. This issue limits the achievable maximal cycle efficiency in cases in which

\footnotetext{
* Corresponding author: ph.streit@,oth-aw.de
} 
higher waste heat temperatures are available, like in the glass, steel or cement industry or downstream of a biogas engine. Water as a working fluid does not suffer from this limitation. Furthermore, water cannot burn, is not toxic, does not spoil the atmosphere and is significantly cheaper than any organic working fluid. Thus, the research project in which the reported work has been carried out aims for a small steam Rankine cycle with about $50 \mathrm{~kW}_{\mathrm{el}}$ power using a micro turbine as an expander [4]. The major goal of the current project is to reduce specific costs $(€ / \mathrm{kWel})$ of the existing WHR system [5].

The challenge of designing a steam turbine for small shaft power $\left(<100 \mathrm{~kW}_{\mathrm{el}}\right)$ is at least twofold. As pointed out by Macchi \& Astolfi [2], steam provides a very high isentropic enthalpy drop for a given maximum and minimum cycle temperature compared to any organic fluid. The specific work $\Delta \mathrm{h}_{\text {is }}$ which can be processed by one turbine stage is equal to a constant $C$ times the square of the rotational speed u on mean diameter $D$, i.e proportional to $u^{2}$ (see Table 1). This is true for any turbine. The value of the constant $C$ depends on the turbine type. Live steam parameters are $400{ }^{\circ} \mathrm{C} / 17.5$ bar in the current project. Exhaust or condensing pressure is 0.2 bar $\left(60^{\circ} \mathrm{C}\right)$, steam mass flow rate is about $80 \mathrm{~g} / \mathrm{s}$. So, the isentropic enthalpy drop, which must be processed by the turbine, is about $880 \mathrm{~kJ} / \mathrm{kg}$ [6]. If the constant $C=1$, what is true for a $50 \%$ reaction turbine stage, $u=938 \mathrm{~m} / \mathrm{s}$ (Table 1 ). Such a high value of $u$ is not feasible. The wheel would burst due to centrifugal forces - no matter which material is used.

The second challenge in designing micro steam turbines is caused by the high enthalpy drop as well. The power of a turbine is equal to the mass flow rate times the enthalpy drop. Thus, the higher the enthalpy drop, the smaller the mass flow rate for a given or required power. The mass flow rate determines the wheel diameter $D$ and the blade height $h_{\text {blade, }}$ which are the main dimensions of the turbine. The diameter $D$ should be as big as possible to achieve a high $u$ combined with an acceptable angular velocity $\omega$ or rotational speed $n$, respectively. However, this leads to very small blade heights, which limits this approach. To sum up, the smaller the aimed power output and thus the corresponding mass flow rate, the smaller the turbine wheel diameter $D$ and thereby the higher the angular velocity or rotational speed must be.

In small turbines for power output $<100 \mathrm{~kW}_{\mathrm{el}}$, the rotational speed is in the magnitude of several $10^{4} \mathrm{rpm}$ [5,7-9]. This fact makes bearing design and generator design challenging. Sophisticated aerodynamic or magnetic bearings must be applied $[5,10])$ and a high speed generator must be employed, which is expensive and contributes typically two third to the specific costs $(€ / \mathrm{kW})$ of a small turbo generator. Of course, these physical obstacles can be overcome by a multi-stage design like in big steam power plants $(10-1000 \mathrm{MW})$. Unfortunately, this solution is too costly and too laborious for those small machines. Therefore, the authors looked for other approaches. In the history of turbomachines [11,12], various turbine architectures have been introduced and were employed till the concentration of power generation started at the beginning of the $20^{\text {th }}$ century. The multi-stage axial turbine has finally prevailed in huge thermal power plants of the several $100 \mathrm{MW}$ class.

Already when the steam turbine started to displace the piston steam engine at the end of the $19^{\text {th }}$ century, three different main turbine concepts existed. There was the simple impulse turbine of de Laval [13] (Table 1). It can be easily derived that its stage enthalpy drop is $2 x$ $u^{2}$ in such an impulse stage without pressure drop across the buckets [14]. Therefore, for the given project boundary conditions $\left(400^{\circ} \mathrm{C}, 17.5 \mathrm{bar}, 0.2 \mathrm{bar}, 0.080 \mathrm{~kg} / \mathrm{s}\right.$ steam), the required circumferential speed is $663 \mathrm{~m} / \mathrm{s}$ compared to $938 \mathrm{~m} / \mathrm{s}$ of the $50 \%$ reaction turbine, which was introduced originally by Parsons [15] (Table 1).

Thanks to the constant pressure over the rotor blading, impulse and Curtis stages can be designed to work with partial admission. This means that a part of the total arc of the annulus is blocked off. The small mass flow rate is concentrated on a section of the rotor wheel. Thereby, too small blade heights can be avoided $[8,14]$. 
The third well-known turbine concept is the velocity compounded Curtis stage [16]. The nozzles and the first wheel might be considered to be identical to the described impulse stage, however, the main difference is the required circumferential speed $u$, which is only half of that of the impulse stage. Thus, the required circumferential speed is only $331 \mathrm{~m} / \mathrm{s}$ which is feasible with a steel wheel (Table 1). It has to be mentioned, that the efficiency potentials of these three turbine architectures differ significantly. Due to higher relative Mach numbers, higher necessary flow deflections compared to a reaction turbine, the impulse turbine achieves only about $80 \%$ efficiency, the Curtis about $70 \%$ compared to $90 \%$ of the reaction turbine. All these turbine concepts can and have been implemented by an axial or by a radial architecture. The radial architecture might be considered to be advantageous because it supports stage enthalpy processing by the centrifugal pressure field for a radial inflow turbine [14]. In contrast, volume flow rate increase due to expansion is facilitated in a radial outflow turbine [17].

In the current project, the authors have investigated analytically and by an in-house 1D turbine design tool (1DTDT) [18] various un-common turbine architectures like multi-stage radial-outflow turbines [17], quasi-impulse cantilever turbines [19] and radial inflow Curtisturbines for the given expansion task $\left(400{ }^{\circ} \mathrm{C} / 17.5 \mathrm{bar}, 0.2 \mathrm{bar}\right.$, about $80 \mathrm{~g} / \mathrm{s}$ steam). Few uncommon turbine architectures have been promising from an aerodynamic point of view. However, mechanical pre-investigation showed that only the presently implemented architecture, a two-wheel axial Curtis-turbine [5], is actually feasible. It is equipped with a titanium rotor. Thus, the authors aim for an improved axial Curtis turbine with increased efficiency and reduced costs compared to its predecessor. In the following, the parameterized, mainly numerical design of this turbine is introduced and discussed.

Table 1 Comparison of different turbine concepts and their velocity triangles for the same stage enthalpy drop $\Delta h_{i s}$ (value of $\mathrm{u}$ for the given project boundary conditions)

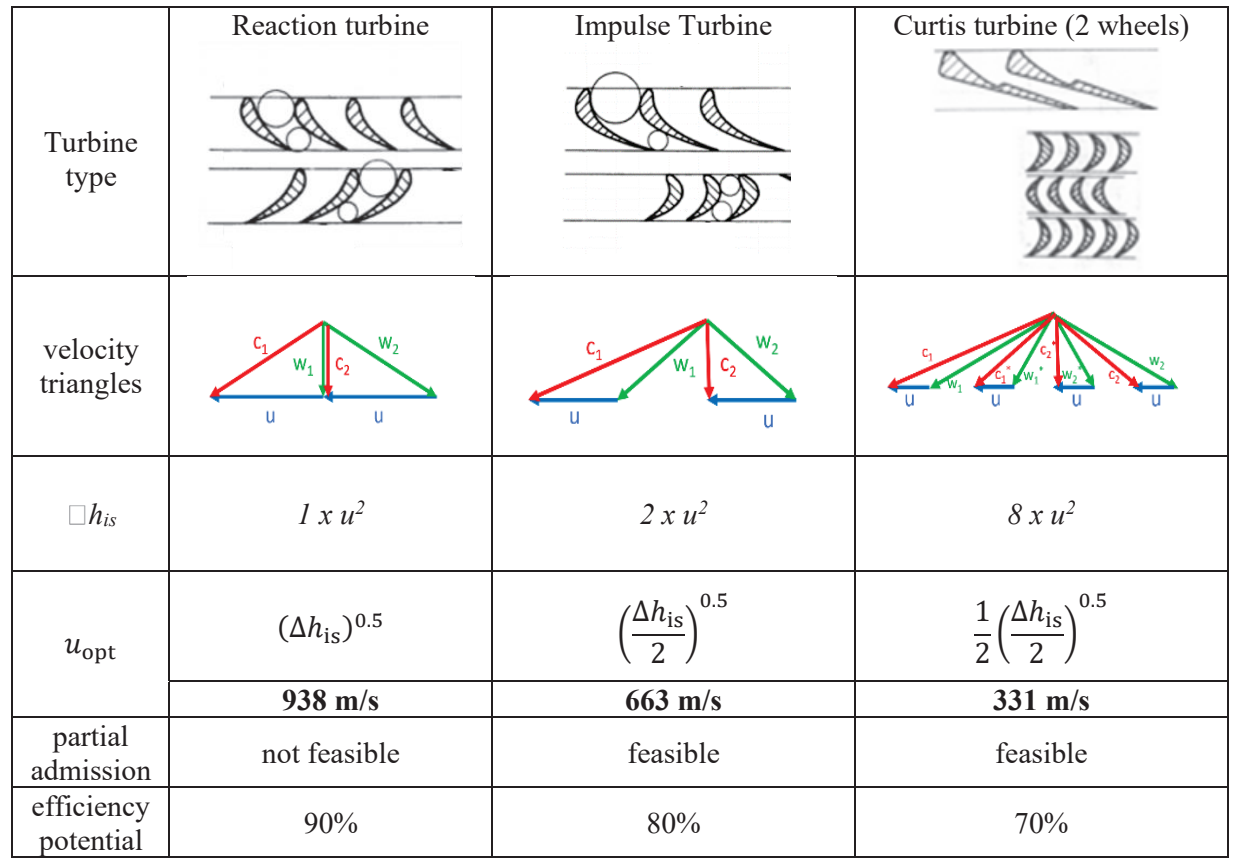




\section{Methodology}

\subsection{D Turbine design tool (1DTDT)}

In order to comprehensively and reliably assess and compare different turbine concepts, a computational tool has been developed for the following considered turbine concepts:

- Axial and radial (cantilever quasi) impulse turbines

- Axial or radial two-wheel velocity compounded Curtis turbines

- Radial inflow, axial outflow reaction turbines $\left(90^{\circ} \mathrm{IFR}\right)$

It has been developed so that the main geometry data and the efficiency of a turbine can be assessed automatically and quickly with the following inputs to the model:

- Working fluid and mass flow rate

- Pressure at the turbine inlet and outlet and temperature at the inlet

- Wheel mean diameter and rotational speed

The tool is based on a 1D meanline model with an in-house developed appropriate simple loss model, which is described in more detail in [20,21]. The 1DTDT calculates efficiency and power output. The loss model for nozzles and buckets allows the prediction of the static thermodynamic conditions of the working fluid at the nozzle throat, nozzle exit and at the blading inlet and outlet by applying REFPROP fluid properties [6]. Hence, the velocity triangles at the mean diameter and the required cross areas can be determined in the form of nozzle angle, height and width, blade height and the blade angle at inlet and outlet. Based on these few geometry specifications, an experienced designer is able to build up the 3D model of the turbine in CAD. With the available 3D CAD model of the turbine, the next design step, the analysis and optimization of the turbine flow by means of Computational Fluid Dynamics (CFD), can be carried out. The turbine design data of the 1DTDT is shown in Table 2.

Table 2. Turbine main design data

\begin{tabular}{|l|c|c|}
\hline \multicolumn{1}{|c|}{ Parameter } & Unit & Curtis-Steam-Turbine \\
\hline working fluid & - & steam \\
\hline wheel diameter $D_{\text {mean }}$ & $\mathrm{mm}$ & 160 \\
\hline rotational speed $n$ & $\mathrm{rpm}$ & 36,000 \\
\hline degree of admission $\varepsilon$ & $\%$ & 35 \\
\hline design pressure ratio PR (ts) & - & 87.5 \\
\hline degree of reaction $r$ & $\%$ & 20 \\
\hline nozzle exit Mach number $M a_{2}$ & - & 2.22 \\
\hline rotor inlet relative Mach number $M a_{r 2}$ & - & 1.62 \\
\hline stator inlet absolute Mach number $M a_{1}$ & - & 0.56 \\
\hline stator outlet absolute Mach number $M a_{2} *$ & - & 1.19 \\
\hline rotor inlet relative Mach number $M a_{r 2} *$ & - & 0.68 \\
\hline expected shaft power & $\mathrm{kW}$ & 38 \\
\hline $\begin{array}{l}\text { predicted total to static isentropic efficiency } \\
\text { (1D loss model) } \eta_{t s, 1 D}\end{array}$ & $\%$ & 53.6 \\
\hline
\end{tabular}




\subsection{CFD Physical models and boundary conditions}

To carry out these analysis and turbine optimizations, appropriate CFD software has to be chosen. For that reason, the software Fine/Turbo by NUMECA [22] which the authors already used for previous investigations [23,24], was used for the simulations. For the rotor stator interface, a full non-matching frozen rotor was used. As a turbulence model, the Spalart-Allmaras model was applied. The turbine has to be meshed $360^{\circ}$ because due to the partial admission, it is not possible to simulate only a segment of the whole turbine. Table 3 shows the boundary conditions and physical models applied to the CFD simulations.

Table 3. Physical Models and Boundary Conditions of the CFD Simulations

\begin{tabular}{|c|c|}
\hline Model or Condition & Parameter \\
\hline Mathematical Model & Turbulent Navier Stokes \\
\hline Modelling of turbulence & Spalart-Allmaras \\
\hline Rotor-Stator Interface & Full Non-Matching Frozen Rotor \\
\hline Efficiency Definition & Total to Static Isentropic \\
\hline Fluid Model & Water (Condensable Fluid) \\
\hline Inlet Boundary Condition & Absolute Total Pressure (17.5 bar) \\
\hline Outlet Boundary Condition & Static Pressure $(0.2$ bar $)$ \\
\hline
\end{tabular}

\subsection{Mesh study}

To assess and estimate the quality of the mesh, different grid accuracies were analysed and compared to each other. Figure 1 shows the inlet and outlet mass flow rate and the total-tostatic isentropic efficiency over a varying number of grid points for the design boundary conditions. It becomes clear that for a very low number of grid points ( 0.7 Million), the mass flow rate extremely differs from the design mass flow rate $(82 \mathrm{~g} / \mathrm{s})$. The mass flow rate course flattens out at about $81-82 \mathrm{~g} / \mathrm{s}$ at 6.1 up to 53.8 Million grid points. The efficiency varies between $61.54 \%$ and $61.20 \%$ in the case of 53.8 to 6.1 Million grid points, respectively. The efficiency value for 0.7 million grid points is not conclusive due to the high mass flow rate difference. The mesh with 48 Million grid points was used as a compromise between accuracy and computing time. The still non-negligible deviation from inlet to outlet mass flow rate is very likely to be caused by high unsteady effects in the flow field due to partial admission. An unsteady time averaged CFD simulation confirmed these assumptions since a smaller deviation could be achieved ( $82 \mathrm{~g} / \mathrm{s}$ at the inlet and $82.8 \mathrm{~g} / \mathrm{s}$ at the outlet). 


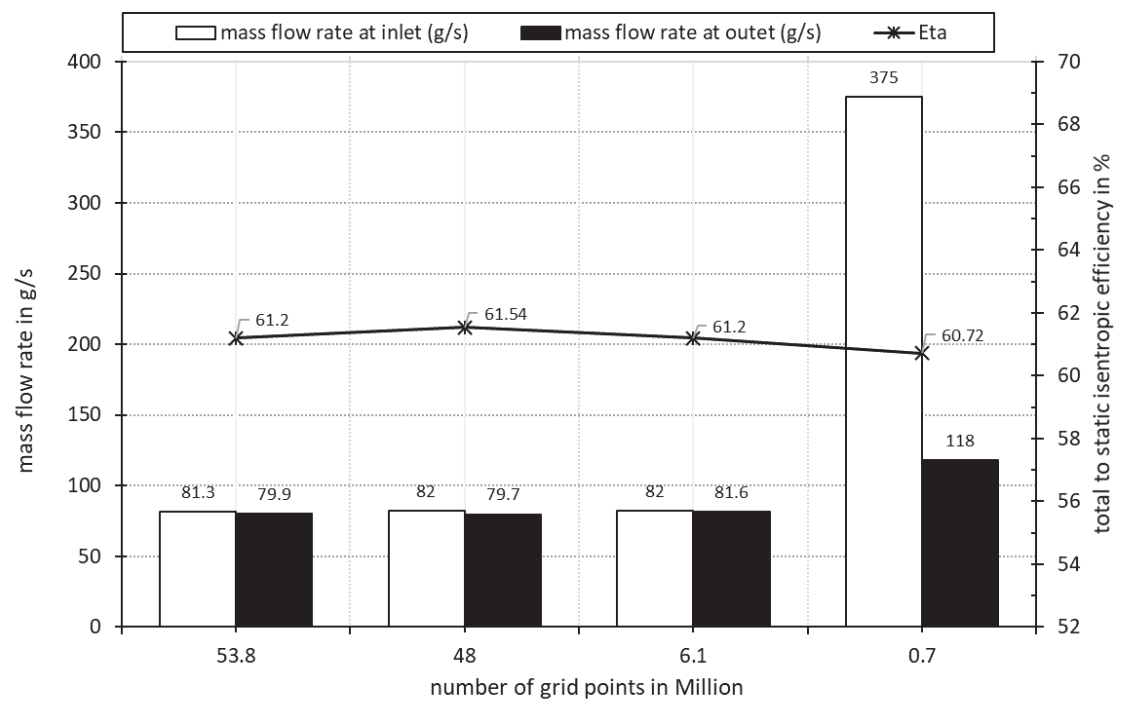

Fig. 1. Mass flow rate and total to static isentropic efficiency as a function of the number of grid points

\subsection{Parameterized turbine design}

In Figure 2 (top), the axial pressure distributions through the whole turbine at specific axial positions for different versions of the Curtis meridional flow channel are shown. The dotted line with the squared markers (1D-Design (15\%)) and the dotted line with the triangular markers (1D-Design (20\%)) show the static pressure evolution designed by means of the 1DTDT. The solid line with squared markers (CFD V1 (15\%)) and the solid line with the triangular markers (CFD V16 (20\%)) represent the pressure distributions achieved by 3DCFD simulations. It has to be addressed that in the parametrization process, the reaction in the stator wheel was up scaled from $15 \%$ to $20 \%$ - the versions in Fig. 2 are named accordingly. If the degree of reaction is at $15 \%$, it implies that $85 \%$ of the entire turbine isentropic enthalpy drop is converted into kinetic energy in the supersonic nozzles and $15 \%$ in the stator wheel $-20 \%$ reaction follows accordingly. Both wheel passes are originally designed for constant pressure flow in the 1DTDT. The predicted blade heights (1DTDT) should ensure the aimed pressure distribution. However, it becomes clear that there is a large deviation between the designed (1D-Design (15\%)) pressure distribution and the achieved (CFD V1 (15\%)) pressure distribution in 3D-CFD (Fig. 2). The biggest differences occur between the inlet of the first rotor wheel and the stator wheel outlet. In contrast to the constant pressure (impulse) design, the pressure drops from about 0.5 to 0.2 bar over the first rotor wheel in V1. This pressure drop leads to a high reaction in the first wheel and increasing relative velocity over the blade channel. After this pressure drop over the first rotor wheel, the static pressure remains at the outlet conditions till the outlet area. 

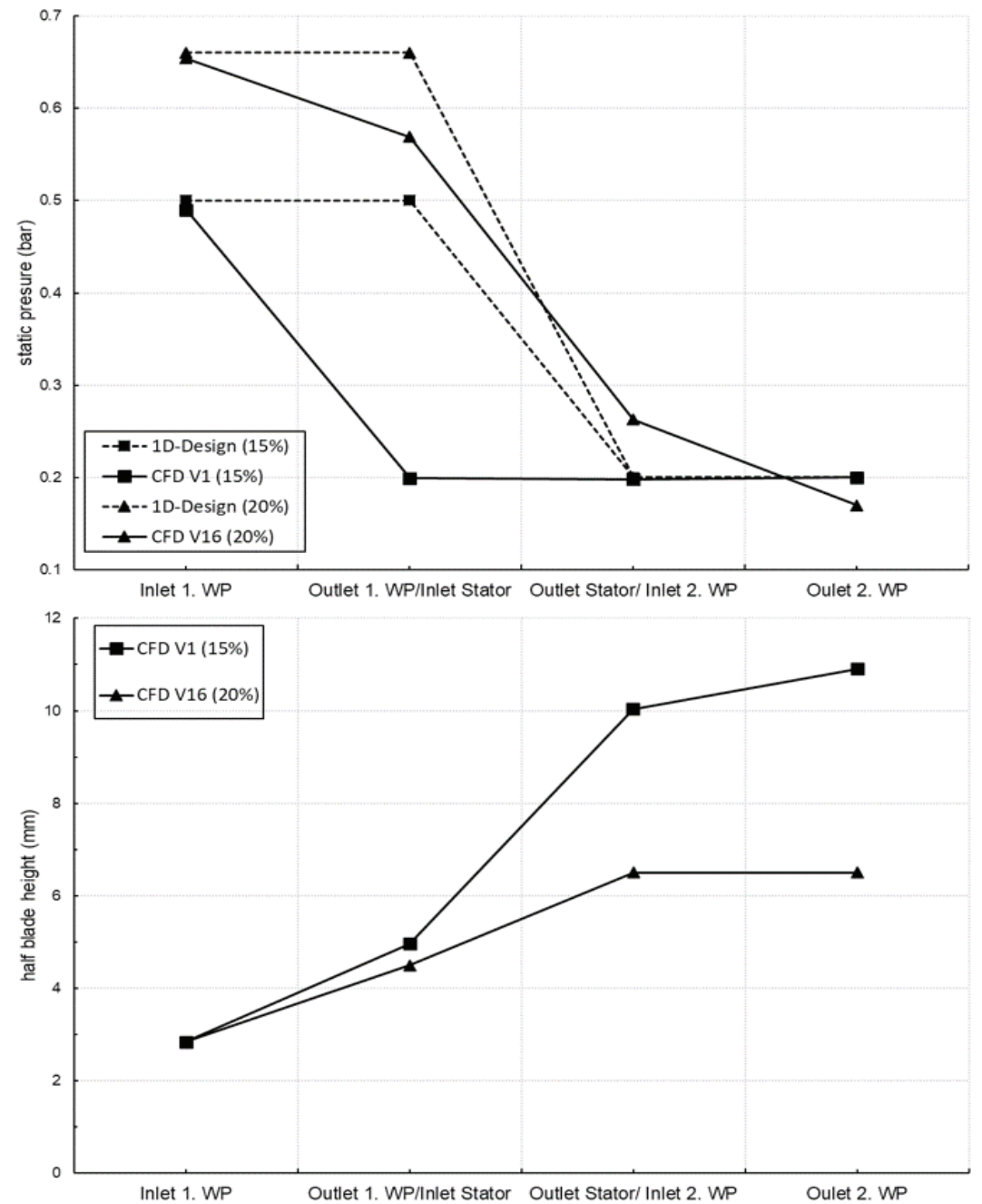

Fig. 2. Static pressure (top) and half blade height (bottom) at different positions through the turbine (mean diameter $D_{m}=$ const.)

The origin of the significant deviation between 1D-design and 3D-CFD pressure distributions is the applied 1D loss model. The 1D loss model is not only needed to predict turbine efficiency. Furthermore, it is needed to determine the fluid properties like density at any axial position in the turbine. Thus, too high losses result in too low fluid density and thereby too big flow areas or blade heights, respectively. The loss model of the 1DTDT has mainly been developed and applied previously for single wheel axial and radial impulse turbines, working with organic fluids [21]. So far, deviations this big between 1DTDT and 3D-CFD have not occurred yet. Therefore, the authors decided to continue the optimization of the Curtis turbine directly in 3D CAD and 3D CFD, applying a parameterized design approach.

By adjusting the meridional flow channel or the blade heights (Fig. 2 bottom) step by step, a desired axial pressure distribution (CFD V16, Fig. 2 top) could be achieved. The prismatic blading remained mainly unchanged - besides rounding the leading edges of the stator and second rotor wheel. As mentioned above, reaction or enthalpy drop across the 
stator wheel has been increased from $15 \%$ to $20 \%$. The V16 stator wheel is working as a transonic nozzle. Furthermore, additionally, a slight reaction has been introduced over the two rotor wheel passes, although axial thrust forces should be avoided. This slight streamwise pressure drop should ensure that there is always a small but clearly defined axial force in the streamwise direction on the bearings. The necessary changes in blade heights are significant for the stator wheel and the second rotor wheel but much smaller for the first rotor wheel. This confirms the previous reasonable results for axial and radial impulse turbines [19] designed by the 1DTDT. Total-to-static isentropic efficiency has been increased from $57.5 \%$ (CFD V1) to $61.5 \%$ (CFD V16).

To achieve and to obtain the V16 design, it was necessary to model the turbine in a parameterized way and to iteratively exchange the information between CAD and CFD. The steps, which were necessary for this, are described below in more detail.

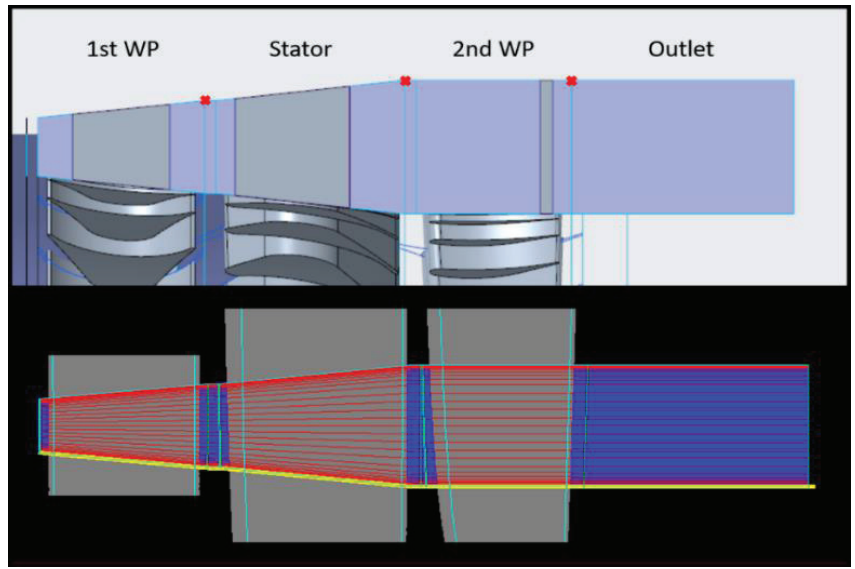

Fig. 3. Comparison of the meridional channel in CAD and CFD

Figure 3 shows the meridional flow channel of the Curtis turbine in the CAD software Creo (top) [25] and in IGG (Interactive Geometry Generator) (bottom) [22], the program to prepare the geometry and to generate the mesh for the CFD simulation. In Fig. 3 (top), the meridional channel in blue and the blades in grey can be seen. The red crosses mark the points where the channel can be adjusted. The height of the turbine outlet changes accordingly to the height at the outlet of the last rotor wheel. The inlet of the first rotor wheel is fixed due to a fixed nozzle outlet height. This simplification was necessary because the expenditure of time for manually meshing a new nozzle geometry was too high. The bottom part of Fig. 3 shows the meridional channel in blue and the blades in grey in the IGG environment. In comparison to the channel and blades at the top of the picture, only the blade heights differ because the meshing process implies prismatic blade geometries, which stand out over the hub and shroud curve of the meridional flow channel. The channel in IGG is taken directly from the CAD software via export/import. In this way, it is possible to adapt the channel in CAD and combine it with the existing blades in IGG. This implementation allows quick geometry adjustments, mesh generation and thereby a quick gain in information. In this way, it was possible, that the geometry, in this case the meridional flow channel, could be changed. The meshing process ran afterwards and the simulation was then started. After the analysis and evaluation of the results received from this CFD simulation, the authors could then adjust the geometry and start the entire process again. The CFD simulation needed about $8 \mathrm{~h}$ so that the overall turn-around-time for one geometry modification was about one working day (including the night for CFD calcs). 


\section{Results}

Due to a high expenditure of time, not all of the different versions of the turbine could be analysed in detail. Because of this reason, only the most prospective version of the turbine is analysed in the following.

\section{CFD Contour plots}

Figure 4 shows the absolute (top) and relative (bottom) Mach number distribution for the V16 at 36,000 rpm and the design pressure ratio at $50 \%$ blade height. The nozzles accelerate continuously as designed, with little anisotropic flow at the outlet to about Mach 2.5 to Mach 3. The flow passes through the first rotor wheel with shockwaves, probably induced by the leading edges of the rotor blades. Flow separation occurs at the suction side of some of the blades, and the flow stays attached at the pressure side. For the stator wheel, the flow enters the channel with sub- to transonic flow and accelerates steadily to about Mach 1.5 to Mach 2 in the absolute reference frame. The flow then passes through the second rotor wheel and exits the turbine through the outlet with about Ma 0.7. Surely, this flow field is representing one specific position of the frozen rotor-stator interface. The results should not be overrated, but nevertheless, the chosen approach is reliable and quick enough to be applied in a reasonable turbine design process.

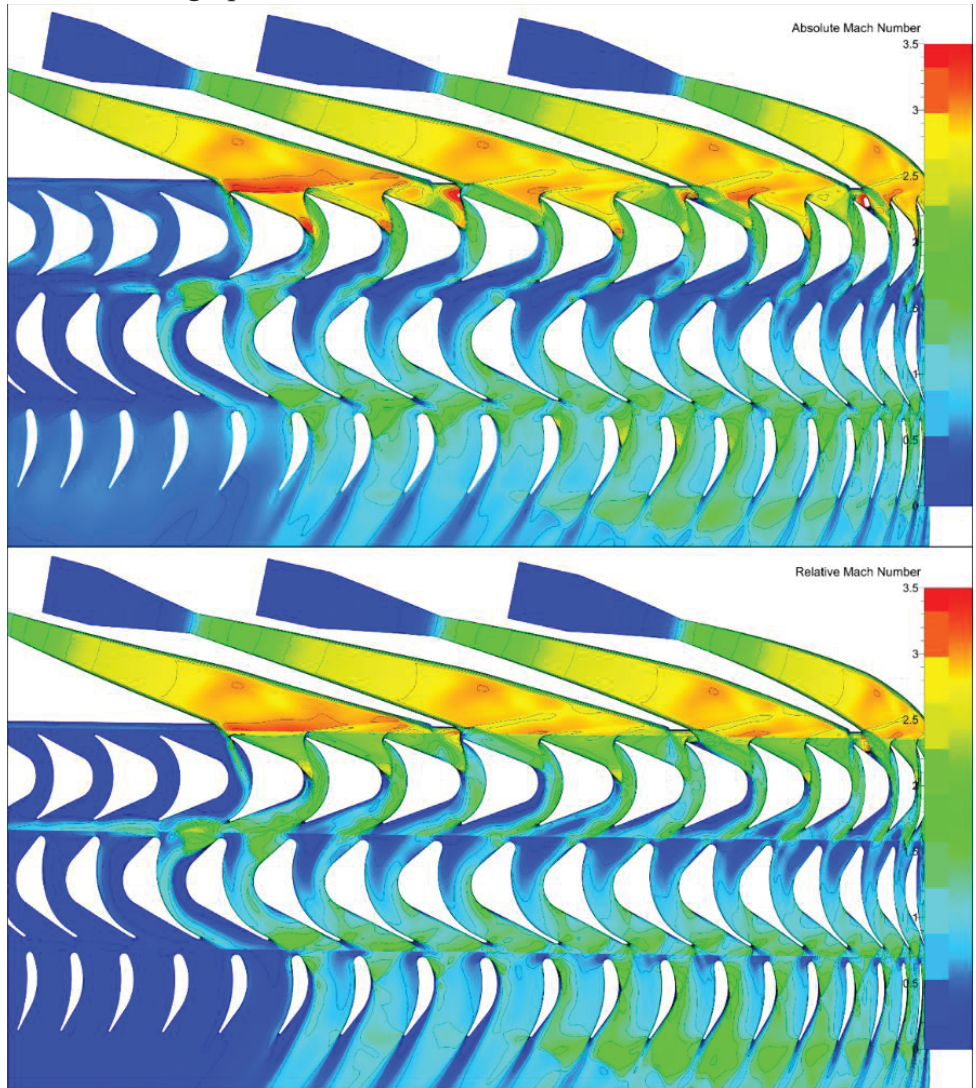

Fig. 4. Absolute (top) and Relative (bottom) Mach number plots for V16 at 36,000 rpm and design pressure ratio (87.5) 


\subsection{CFD Performance maps}

The designed Curtis turbine will not constantly work under design conditions in the WHR plant. Condensing pressure and thereby overall turbine pressure ratio (PR) will vary, e.g. due to seasons. In order to diminish efficiency losses due to varying PR, the rotational speed of the turbine is usually adapted. Therefore, efficiency characteristics of V16 are generated by means of the described CFD approach.

The total to static isentropic efficiency as a function of the rotational speed of the V16 is shown in Figure 5. The maximum rotational speed of 36,000 rpm at the design point was chosen due to mechanical integrity limitations. Generally, the efficiency shows a comprehensible behavior over the entire rotational speed range. The efficiency of the turbine increases with rotational speeds, $63 \%$ are achieved at the highest considered rpm of 39,000, which are not allowed in actual operation (mechanical integrity). The entire course lies on a too high efficiency level from approx. $53 \%$ to $62 \%$, because not all physics are considered. Although the $360^{\circ} \mathrm{CFD}$ simulation takes into account steam leakages at the beginning and the end of the impinged part of the rotor wheels, unsteady effects are not considered. Furthermore, the tip gaps of the rotor wheels and the hub gap of the stator wheel are not modelled - as can be seen in Fig. 3 - due to CFD performance reasons.

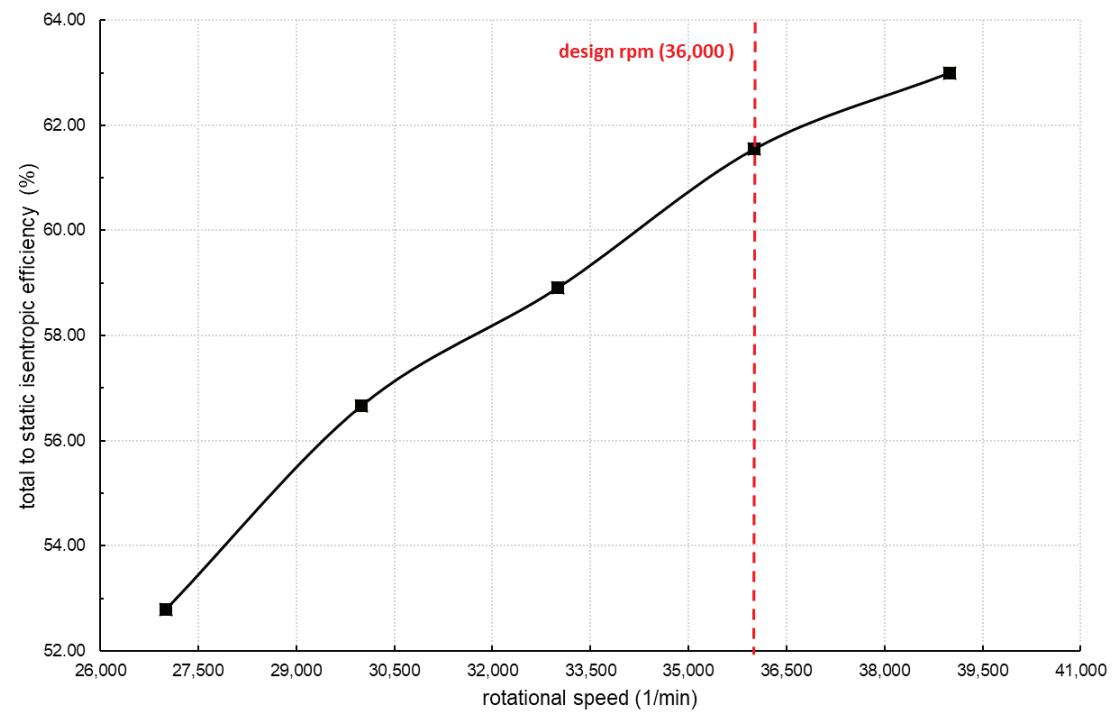

Fig. 5. Total to static isentropic efficiency as a function of the rotational speed for the V16

Figure 6 depicts the total to static isentropic efficiency as a function of the pressure ratio (PR) for V16. The pressure ratio was adjusted by changing the static pressure at the outlet of the turbine (i.e. condensing pressure, displayed at every point in the figure); the inlet pressure stayed constant at 17.5 bar. From a lower to a higher PR, the efficiency increases up to the design PR of 87.5 (17.5 absolute total inlet pressure and 0.2 bar static outlet pressure) and decreases from this point to a $P R$ of 175 . For pressure ratios lower than approx. $P R=29$, the simulation did not converge because of the high unsteady flow effects and flow separations. For these high outlet pressures, the second rotor wheel even increased the total enthalpy and therefore worked as a compressor instead of a turbine. The efficiency drop for higher than designed pressure ratios can be explained by the inability of the Laval nozzles to convert the available higher enthalpy drop ( $\left.\mathrm{PR}>\mathrm{PR}_{\text {design }}\right)$ into kinetic energy. As expected, the turbine efficiency shows a dependency on the pressure ratio but still performs well in the outlet 
pressure range between 0.15 bar and 0.3 bar. The highest efficiency at the designed PR reinforces the confidence of the authors in their design.

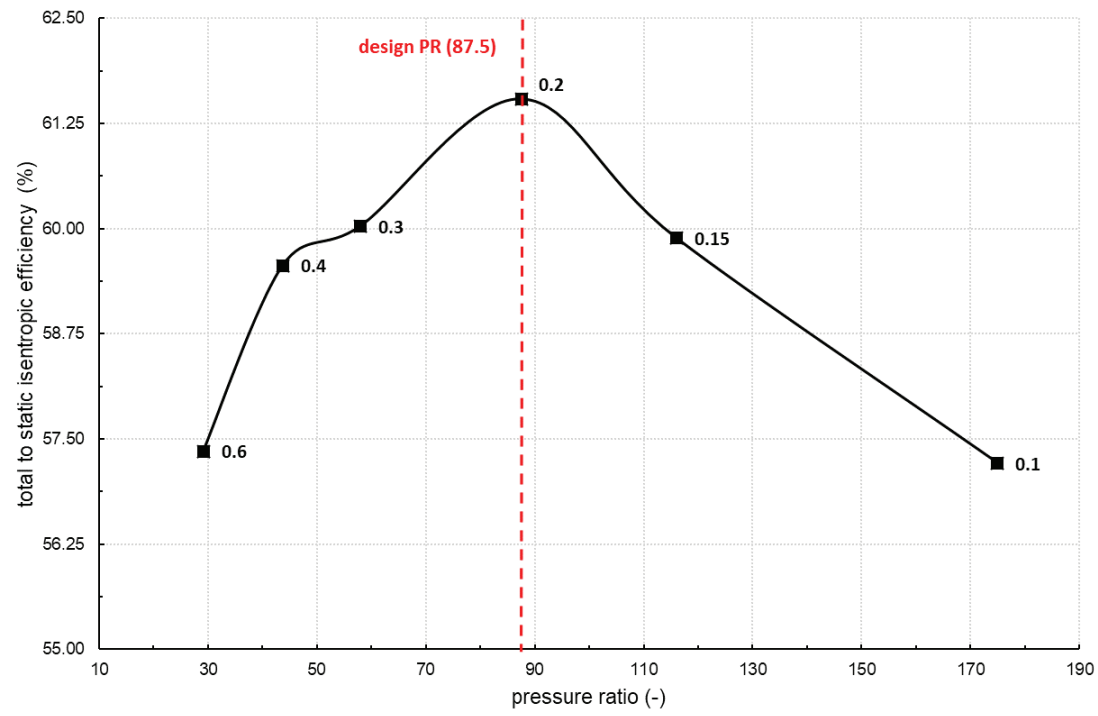

Fig. 6. Total to static isentropic efficiency as a function of the pressure ratio for the V16 with outlet pressures (bar) for every point

\section{Conclusion}

The physical challenges of designing a small-scale steam turbine were repeated. Thereby, it has become clear why a two wheel velocity compounded axial Curtis turbine must be chosen for the given design task. The applied design approach, consisting of an in-house developed 1D turbine design tool and a parameterized 3D CAD/CFD design, was introduced. The shortcomings of the applied 1D loss model and their consequences for the turbine geometry were addressed.

The predicted efficiency (1DTDT) of the V1 was just $53.6 \%$ compared to $57.5 \%$ in $3 \mathrm{D}$ CFD. By adjusting and optimizing the meridional flow channel directly in $3 \mathrm{D}$ space, the desired axial pressure distribution could be achieved with V16. Total to static isentropic efficiency is finally $61.5 \%$ in $3 \mathrm{D}-\mathrm{CFD}$. Thus, the parametric design, directly in 3D space, proved to be a practical and reasonable process for daily turbine development. Mach number contours at design point showed the expected pattern but furthermore, area for improvements. Finally, performance characteristics of the final design (V16) were introduced and evaluated.

The designed axial two-wheel Curtis is currently under construction. For the new design, Titanium for the rotor can be avoided and thereby material and manufacturing costs reduced. The new turbine will be installed 2022 in the WHR plant of the main sewage treatment plant in Nuremberg/Germany. There, the waste heat of two $1 \mathrm{MW}$ biogas engines is converted to $40-50 \mathrm{kWel}$ by means of a micro steam Rankine cycle.

The authors gratefully acknowledge the funding of the joint project KompACT on the technoeconomic optimization of an SRC plant for high temperature WHR by the Federal Ministry for Economic Affairs and Energy in the 6th Energy Research Program on the basis of the decision by the German Bundestag. 


\section{References}

1. Pehnt DM, Bödeker J, Arens M, Jochem DE, Idrissova F. Die Nutzung industrieller Abwärme - technisch-wirtschaftliche Potenziale und energiepolitische Umsetzung: Bericht im Rahmen des Vorhabens „Wissenschaftliche Begleitforschung zu übergreifenden technischen, ökologischen, ökonomischen und strategischen Aspekten des nationalen Teils der Klimaschutzinitiative“. Heidlberg, Karlsruhe; 2010.

2. Macchi E, Astolfi M (eds.). Organic rankine cycle (ORC) power systems: Technologies and applications. Duxford, UK, Amsterdam, Boston, Heidelberg, London, New York, Oxford, Paris, San Diego, San Francisco, Singapore, Sydney, Tokyo: Woodhead Publishing is an imprint of Elsevier; Elsevier; 2017.

3. Tanuma T. Advances in steam turbines for modern power plants. Oxford: Woodhead Publishing; 2016.

4. Raab Florian, Opferkuch Frank, Klein Harald. Dezentrale Verstromung von Abwärme: Forschungsarbeit zur Abwärmenutzung mittels Steam-Rankine-Cycle-Technlogie. In: BWK Energie.

5. Kraus MH, Deichsel M, Hirsch P, Opferkuch F, Heckel C. Hermetic 40-kW-Class Steam Turbine System for the Bottoming Cycle of Internal Combustion Engines. In: ASME Turbo Expo 2016: Turbomachinery Technical Conference and Exposition, June 13-17, 2016, Seoul, South Korea. New York, N.Y.: ASME; 2016.

6. REFPROP: NIST Reference Fluid Thermodynamic and Transport Properties Database (REFPROP). [March 30, 2021]; Available from: https://www.nist.gov/srd/refprop.

7. Seume JR, Peters M, Kunte H. Design and test of a 10kW ORC supersonic turbine generator. J. Phys.: Conf. Ser. 2017;821:12023. https://doi.org/10.1088/17426596/821/1/012023.

8. Klonowicz P, Witanowski Ł, Suchocki T, Jędrzejewski Ł, Lampart P. Selection of optimum degree of partial admission in a laboratory organic vapour microturbine. Energy Conversion and Management 2019;202:112189. https://doi.org/10.1016/j.enconman.2019.112189.

9. Uusitalo A, Honkatukia J, Backman J, Nyyssönen S. Experimental study on charge air heat utilization of large-scale reciprocating engines by means of Organic Rankine Cycle. Applied Thermal Engineering 2015;89:209-19. https://doi.org/10.1016/j.applthermaleng.2015.06.009.

10. Żywica G, Kaczmarczyk TZ, Breńkacz Ł, Bogulicz M, Andrearczyk A, Bagiński P. Investigation of dynamic properties of the microturbine with a maximum rotational speed of $120 \mathrm{krpm}$ - predictions and experimental tests. J VIBROENG 2020;22(2):298-312. https://doi.org/10.21595/jve.2019.20816.

11. Meher-Homji CB. The Historical Evolution Of Turbomachinery 2000:281-322. https://doi.org/10.21423/R1X948.

12. Stodola A. Die Dampfturbinen: Mit einem Anhang über die Aussichten der Wärmekraftmaschinen und über die Gasturbine. 1st ed. Berlin: Springer; 2012.

13. De Laval CGP. Steam Turbine: Patent $(522,066) ; 1889$.

14. Weiß AP. Volumetric expander versus turbine - which is the better choice for small ORC plants? In: University of Liège and Ghent University, editor. ASMEORC2015: Proceedings of the 3rd International Seminar on ORC Power Systems; 2015. 
15. Harris FR. The Parsons Centenary - a Hundred Years of Steam Turbines. Proceedings of the Institution of Mechanical Engineers, Part A: Power and Process Engineering 1984;198(3):183-224. https://doi.org/10.1243/PIME_PROC_1984_198_024_02.

16. OMERSCALES EFC. The Vertical Curtis Steam Turbine. Transactions of the Newcomen Society 1990;62(1):157-8. https://doi.org/10.1179/tns.1990.008.

17. Spadacini C, Rizzi D. Radial outflow turbines for Organic Rankine Cycle expanders. In: Macchi E, Astolfi M, editors. Organic rankine cycle (ORC) power systems: Technologies and applications. Duxford, UK, Amsterdam, Boston, Heidelberg, London, New York, Oxford, Paris, San Diego, San Francisco, Singapore, Sydney, Tokyo: Woodhead Publishing is an imprint of Elsevier; Elsevier; 2017, p. 335-359.

18. Weiß AP, Popp T, Zinn G, Preißinger M, Brüggemann D. A micro-turbine-generatorconstruction-kit (MTG-c-kit) for small-scale waste heat recovery ORC-Plants. Energy 2019;181:51-5. https://doi.org/10.1016/j.energy.2019.05.135.

19. Weiß AP, Popp T, Müller J, Hauer J, Brüggemann D, Preißinger M. Experimental characterization and comparison of an axial and a cantilever micro-turbine for smallscale Organic Rankine Cycle. Applied Thermal Engineering 2018;140:235-44. https://doi.org/10.1016/j.applthermaleng.2018.05.033.

20. Weiß AP, Novotný V, Popp T, Zinn G, Kolovratník M. Customized Small-Scale ORC Turbogenerators- Combining a 1D-Design Tool, a Micro-Turbine-Generatorconstruction-kit and Potentials of 3D-Printing. In: The National Technical University of Athens, editor. ORC2019: Proceedings of the 5th International Seminar on ORC Power Systems; 2019.

21. Weiß AP, Novotný V, Popp T, Streit P, Špale J, Zinn G et al. Customized ORC micro turbo-expanders - From 1D design to modular construction kit and prospects of additive manufacturing. Energy 2020;209:118407. https://doi.org/10.1016/j.energy.2020.118407.

22. NUMECA International - FINETM/Turbo. [March 30, 2021]; Available from: https://www.numeca.com/en_eu/product/fineturbo.

23. Streit P, Popp T, Weiß AP. Simulation and analysis of the performance map of a micro-ORC-turbine - Comparison with measurements. In: 18th Conference on Power System Engineering, Thermodynamics \& Fluid Flow: PSE 2019.

24. Streit P, Popp T, Winkler J, Scharf R, Wei $\beta$ AP. Numerical and experimental investigation of different technologies for adjusting the swallowing capacity of a cantilever ORC turbine. In: THERMOPHYSICAL BASIS OF ENERGY TECHNOLOGIES (TBET 2020). AIP Publishing; 2021, p. 70001.

25. PTC Creo Parametric. [March 30, 2021]; Available from: https://www.pdsvision.com/de/ptc-creo. 